\title{
Species identification of stranded seaweeds on eastern seashores of Thailand and utilization as a sole carbon source for single cell oils synthesized by oleaginous yeasts
}

\author{
AIYA CHANTARASIRI \\ Faculty of Science, Energy and Environment, King Mongkut's University of Technology North Bangkok. Rayong Campus, Rayong 21120, Thailand. \\ Tel./fax.: +66-38-627000 ext. 5400. “email: aiya.c@ sciee.kmutnb.ac.th
}

Manuscript received: 20 April 2020. Revision accepted: 4 May 2020.

\begin{abstract}
Chantarasiri A. 2020. Species identification of stranded seaweeds on eastern seashores of Thailand and utilization as a sole carbon source for single-cell oils synthesized by oleaginous yeasts. Biodiversitas 21: 2353-2361. Many stranded seaweeds are left to decompose on the seashore. This study aimed to identify and utilize the stranded seaweeds collected from seashores in Rayong Province on the east coast of Thailand. Seaweeds were identified as Dictyota dichotoma strain A and Padina australis strain B based on their distinctive morphology and 18S rDNA sequence analyses. The most abundant seaweed, D. dichotoma strain A, was analyzed for chemical compositions following AOAC standard methods. This seaweed was considered a low-cost carbon source for the cultivation of three oleaginous yeasts without any other nutrient supplements. All oleaginous yeasts utilized the carbon source from Dictyota medium for growth and accumulation of single-cell oils (SCOs). The oleaginous yeast, Cryptococcus albidus strain TISTR 5103 accumulated SCOs at $51 \%(\mathrm{w} / \mathrm{w})$. The resulting SCOs from oleaginous yeasts comprise many fatty acids with 10 to 22 carbon atoms. This study is the first to identify stranded seaweeds in Rayong Province using morphological and genetic techniques. Results showed the potential application of stranded seaweeds as a low-cost carbon source for SCO biosynthesis of oleaginous yeasts.
\end{abstract}

Keywords: Cryptococcus albidus, Dictyota dichotoma, oleaginous yeast, seaweed, single cell oil

\section{INTRODUCTION}

Seaweeds or marine macroalgae are autotrophic organisms consisting of a wide variety of species that grow in marine environments. Seaweeds can be split into three taxonomic groups that have different pigment compositions as Chlorophyta (green algae), Rhodophyta (red algae), and Ochrophyta (brown algae) (Mantri et al. 2020). Seaweeds are commonly valued as animal feed, human food and also used in industrial applications such as biofuels, chemicals, cosmetics, fertilizers, gels and stabilizers, papers, and medicines (Buschmann et al. 2017; Kim et al. 2017). Five genera of seaweeds are globally cultivated including Saccharina (brown alga), Undaria (brown alga), Porphyra (red alga), Eucheuma/Kappaphycus (red alga) and Gracilaria (red alga) (Buschmann et al. 2017). In their natural environment, seaweeds are usually attached to rocks and reefs with their holdfast structure. Strong storms, herbivores, and ocean waves cause seaweeds to detach and some species with high buoyancy remain afloat (López et al. 2018). Detached floating seaweeds are eventually washed up on seashores. Stranded seaweeds that are considered as edible may be harvested for domestic purposes, while the remainder negatively impacts coastal ecosystems due to their foul-smelling decay processes.

Thailand is situated at the center of the Indochinese Peninsula, bordered to the east and south by the Gulf of Thailand and to the west and south by the Andaman Sea. Seaweed beds are distributed widely along the Thai coastline as one of the country's marine fishery resources
(Petsut et al. 2012). Studies of seaweeds in Thailand and the Indo-Pacific region have examined the cultivation and nutrition of some edible seaweeds such as Gracilaria and Caulerpa (green alga) (Prathep et al. 2011; Gaillande et al. 2017). Previous investigations have focused on biodiversity hotspots along the Gulf of Thailand and the Andaman Sea in Southern Thailand (Prathep et al. 2011; Chankaew et al. 2016; Seangkaew et al. 2016), with scant research on nonedible and low-value stranded seaweeds in Eastern Thailand.

Seaweeds can be used as a potential feedstock for many biorefineries. The carbohydrate content of seaweeds can be converted into high-value organic chemicals and also utilized as an organic carbon source for lipid bioproduction by oleaginous yeasts. These biosynthesized lipids can be converted into biodiesel by the transesterification process (Sadhukhan et al. 2019). Oleaginous yeasts comprise a small group of microorganisms that can utilize organic carbon and accumulate large amounts of oil droplets, mainly in the form of triacylglycerol, in their cellular compartments (Fakas 2017; Patel et al. 2017). Species that are considered as oleaginous are able to accumulate more than $20 \%$ of their dry biomass as intracellular lipids, and biosynthesis of microbiological lipids is defined as singlecell oils (SCOs) (Gientka et al. 2017). Effective oleaginous yeasts belong to the genera Candida, Cryptococcus, Lipomyces, Rhodosporidium, Rhodotorula, Trichosporon, and Yarrowia (Patel et al. 2017; Qin et al. 2017). Several seaweed species have been studied as potential feedstock for SCO production by various oleaginous yeasts such as 
Laminaria japonica (S. japonica) and S. latissimi (Xu et al. 2015; Zhang et al. 2016; Abeln et al. 2019). However, previous studies have only focused on edible high-value seaweeds in genera of Laminaria (Saccharina). The utilization of non-edible stranded seaweeds as a low-cost feedstock in biorefinery applications is challenging.

Here, seaweeds that detached from their beds and washed up on the shores of Rayong Province in Eastern Thailand were collected and identified. The Rayong Province seashore is ecologically important, but knowledge of seaweed diversity remains limited. The most abundant seaweed, Dictyota dichotoma strain A, was considered a non-edible seaweed. The seaweed composition was analyzed and used as the sole carbon source for the cultivation of three different oleaginous yeasts with no added nutrient supplements. Contents and fatty acid composition of the SCOs produced from the oleaginous yeasts were determined.

\section{MATERIALS AND METHODS}

\section{Study area}

The study area was located at the adjoining seashores of two Districts in Rayong Province in the east of Thailand The study area was located at the adjoining seashores of two Districts in Rayong Province in the east of Thailand comprising Hadd Nam Rin Beach $\left(12^{\circ} 40^{\prime} 31^{\prime \prime} \mathrm{N}, 101^{\circ} 5^{\prime}\right.$ $32^{\prime \prime}$ E) in Banchang District and Haad Son Krasip Beach in Mueang Rayong District ( $\left.12^{\circ} 40^{\prime} 42^{\prime \prime} \mathrm{N}, 101^{\circ} 5^{\prime} 59^{\prime \prime} \mathrm{E}\right)$. The beaches are not in the marine reserve area of the Gulf of Thailand, and nearby Map Ta Phut Industrial Port (Figure 1). The shores comprise sandy beaches alternated with a few rocky reefs. Coastal plants are predominantly beach morning glory (Ipomoea pes-caprae), ironwood horsetail (Casuarina junghuhniana), and sea almond (Terminalia catappa). Some areas of the study seashores have been converted by the local communities into street stalls.

\section{Procedures \\ Sampling of seaweeds}

The stranded seaweeds were randomly collected from the study area during the winter season in February 2018. Strong winds and ocean waves during winter often detach the seaweeds from their beds. Samples were taken along the coastlines of Hadd Nam Rin Beach and Haad Son Krasip Beach every 100 meters using a sampling quadrat $(50 \times 50 \mathrm{~cm})$. The sampling distance was two kilometers as the length of the two beaches. The stranded seaweeds lying on the study shores are shown in Figure 2. The collected seaweeds were rinsed with water and stored in sterilized plastic bags. They were primarily categorized and identified by their dominant morphology and pigmentation based on seaweed pictures in the reference book, Seaweeds and Seagrasses of the Southern Andaman Sea coast of Thailand (Coppejans et al. 2017). Seaweed blades and stipes were cleaned using sterilized water several times to remove epiphytes, fauna, sand particles, and plastic debris. They were then sun-dried for 72 hours before drying in an oven at $60^{\circ} \mathrm{C}$ for 48 hours. Dried seaweeds were weighed and comminuted to fine powder of $500 \mu \mathrm{m}$ particle size.

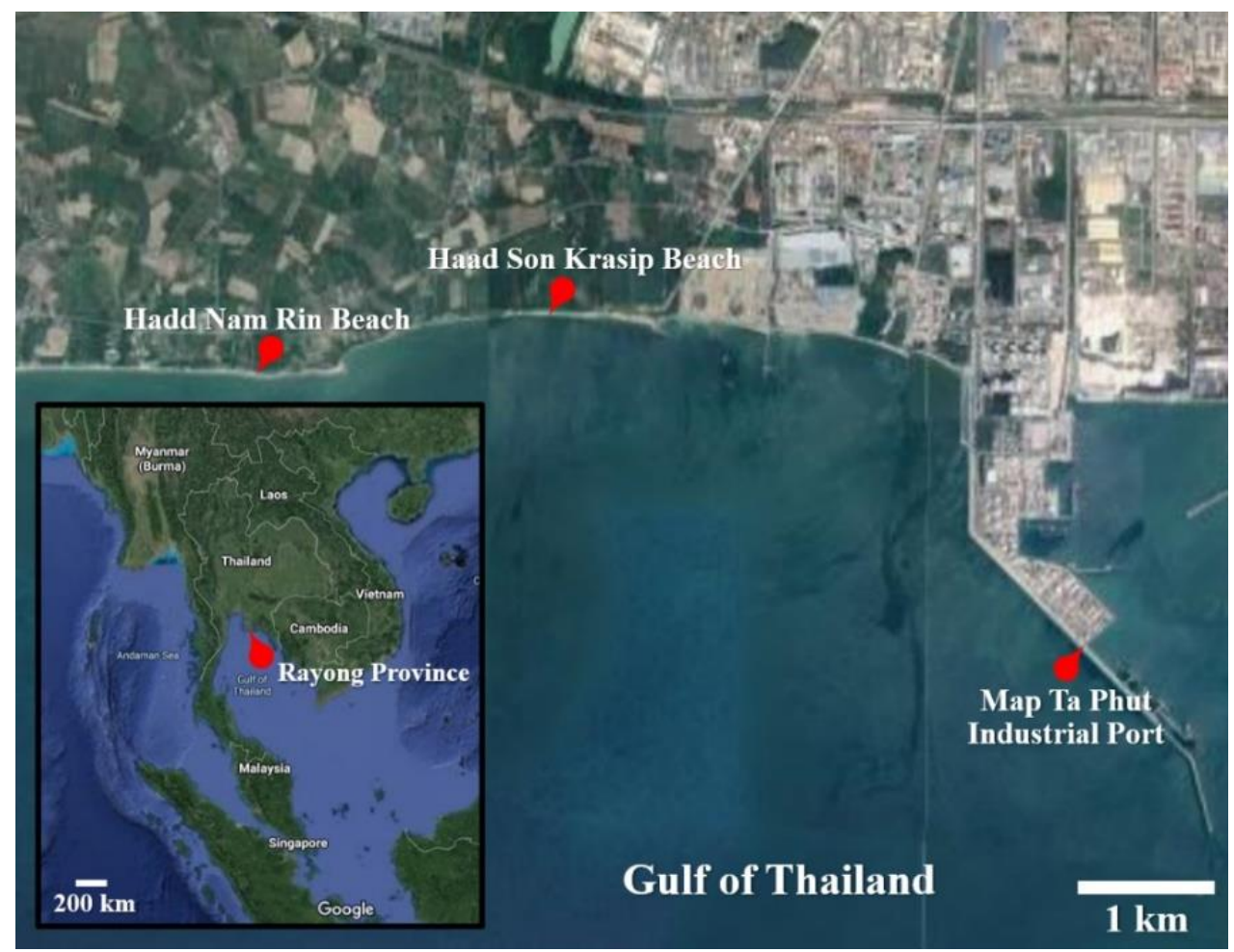

Figure 1. Location of Hadd Nam Rin Beach and Haad Son Krasip Beach in Rayong Province, Thailand generated from Google Maps 


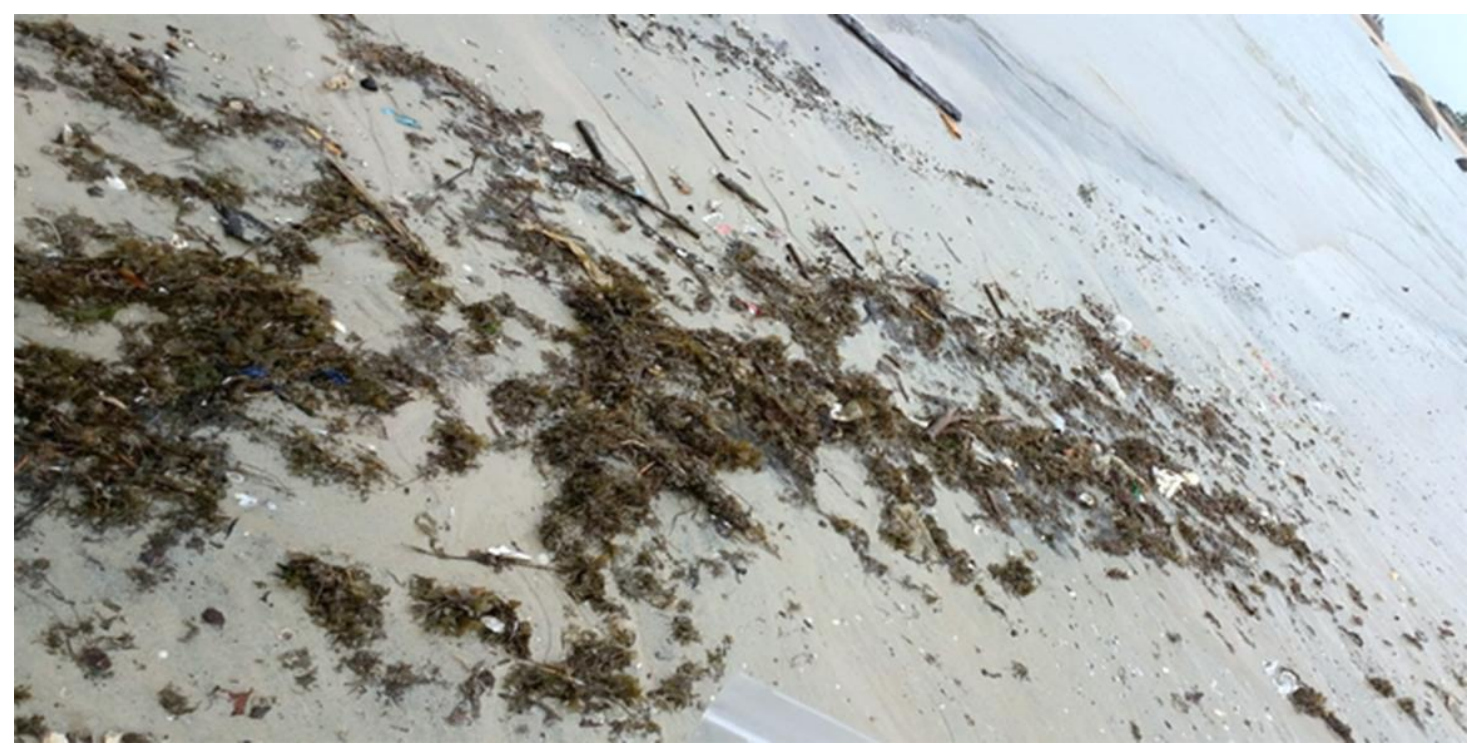

Figure 2. Stranded seaweeds on the study shores in February 2018

\section{Species identification of seaweeds by $18 S$ ribosomal DNA amplification}

Total DNA was exacted from the dried seaweed powder by DNA Trap I kit (DNA TEC, Kasetsart University, Thailand) following the protocol described by DNA TEC. Polymerase chain reaction (PCR) amplification of the $18 \mathrm{~S}$ rRNA region was performed using the OnePCR ${ }^{\mathrm{TM}}$ reaction mixture (Bio-Helix, Taiwan). Primers used for the amplification included a forward primer MA1 (5'CGGGATCCGTAGTCATATGCTTGTCTC-3') and a reverse primer MA2 (5'-CGGAATTCCTTCTGCAGG TTCACC-3') (Sigma-Aldrich, Singapore). Amplification conditions followed the method of Feng et al. (2016) with slight modifications. Conditions involved a preheating step at $95^{\circ} \mathrm{C}$ for 5 minutes, denaturation step at $95^{\circ} \mathrm{C}$ for 1 minute, annealing step at $55^{\circ} \mathrm{C}$ for 45 seconds, extension step at $72^{\circ} \mathrm{C}$ for 1 minute and a final extension step at $72^{\circ} \mathrm{C}$ for 5 minutes. Amplification was performed for 30 cycles in a Mastercycler ${ }^{\circledR}$ Nexus (Eppendorf, Germany). Approximately 1,000-bp PCR products were analyzed using $1.5 \%(\mathrm{w} / \mathrm{v})$ OmniPur $^{\circledR}$ agarose gel (Calbiochem, Germany) and visualized by Novel Juice (Bio-Helix, Taiwan). The PCR ladder used in this study was $1 \mathrm{kbp}$ DNA ladder RTU (Bio-Helix, Taiwan). The 18S rDNA PCR-products were purified and sequenced by the nucleotide sequencing service of Macrogen Inc. (Seoul, Korea). Sequence similarity analysis of the $18 \mathrm{~S}$ rDNA PCR-products was aligned using the BLASTn program (National Center for Biotechnology Information, NCBI). The phylogenetic tree was analyzed by SeaView software version 4.6.4 (Laboratoire de Biométrie et Biologie Evolutive, Université de Lyon, France) and visualized by FigTree software version 1.4.3 (Institute of Evolutionary Biology, University of Edinburgh, UK). The phylogenetic tree was generated by the neighbor-joining (NJ) method with 100,000 bootstraps. All 18S rDNA sequences were deposited in the GenBank database of NCBI under the accession numbers MT291824 and MT291865.
Chemical composition analysis of the model seaweed (Dictyota dichotoma strain A)

The representative seaweed, D. dichotoma strain A was considered as the model seaweed and selected for chemical composition analysis due to its abundance in the study area. Chemical composition analyses of dried seaweed powder were conducted following the standard methods of AOAC International (AOAC, 2016). The analyses comprised moisture content by the oven drying method (AOAC method No. 952.08), total protein by the Kjeldahl method $(\mathrm{N} \times 6.25)$ (AOAC method No. 992.23), total fat by the Soxhlet method (AOAC method No. 948.15 and 945.16), total carbohydrate and total sugars by the liquid chromatographic method (AOAC method No. 982.14) and ash content by the incineration method (AOAC method No. 930.30 and 945.14). All analyses were conducted using the services of the Institute of Nutrition (Mahidol University, Thailand) (service No. SFC 885/2561). All experiments were performed in triplicate.

\section{Preparation of inoculums and culture conditions of oleaginous yeasts}

The oleaginous yeasts used in this experiment were $C$. albidus strain TISTR 5103, $R$. toruloides strain TISTR 5186, and $Y$. lipolytica strain TISTR 5212 obtained from the Thailand Institute of Scientific and Technological Research (TISTR). All yeast inoculums were pre-cultured in YM broth (HiMedia, India) at $30^{\circ} \mathrm{C}$ for 24 hours in a rotary shaker at $150 \mathrm{rpm}$. The culture medium was prepared from dried seaweed powder of D. dichotoma strain A following the method of $\mathrm{Xu}$ et al. (2014) with slight modifications. Thirty grams of dried seaweed powder were mixed in one liter of tap water. The $\mathrm{pH}$ of the seaweed mixture was adjusted to 3.0 with acetic acid, stirred for 6 hours and then left unstirred for 24 hours at room temperature. The seaweed mixture was centrifuged at $3,500 \times \mathrm{g}$ for 15 minutes to remove any solid substances. The supernatant, with no other nutrients supplements, was 
adjusted to pH 5.5 and autoclaved at $121^{\circ} \mathrm{C}$ for 15 minutes. This was considered as the culture medium. A baffled flask containing 1 liter of culture medium was seeded with $10 \%$ $(\mathrm{v} / \mathrm{v})$ of each inoculum. The culture flasks were incubated at $30^{\circ} \mathrm{C}$ for 120 hours in a rotary shaker at $150 \mathrm{rpm}$. One milliliter of culture suspension was collected to measure yeast growth using optical density at $600 \mathrm{~nm}\left(\mathrm{OD}_{600}\right)$ every 24 hours. All experiments were performed in triplicate.

\section{Determination of dry cell weight of oleaginous yeasts}

Yeast cells were collected after 120 hours of incubation by centrifugation at $3,500 \times \mathrm{g}$ for 15 minutes and washed with sterilized $0.85 \% \mathrm{NaCl}$ to remove the culture medium. Cell pellets were re-suspended in sterilized $0.85 \% \mathrm{NaCl}$ and filtered through a pre-weighed $0.45-\mu \mathrm{m}$ nitrocellulose filter (Millipore, USA) using a vacuum pump. Samples on nitrocellulose filters were dried to constant weight at $105^{\circ} \mathrm{C}$ in an oven and then weighed. All experiments were performed in triplicate.

\section{Extraction of SCOs and determination of fatty acid composition}

Extraction of total SCOs was conducted according to Byreddy et al. (2015) by sonication-assisted solvent extraction. Fifty milligrams of dried yeast were suspended in three milliliters of chloroform/methanol $(2: 1, \mathrm{v} / \mathrm{v})$ solution. The sample was sonicated at $20 \mathrm{kHz}$ with $40 \%$ amplitude using a Vibra-Cell ${ }^{\mathrm{TM}}$ ultrasonic liquid processor (Sonics, USA), and the mixture was centrifuged at 3,500 $\times$ g for 15 minutes to partition the SCOs into the solvent. The solvent was then evaporated using nitrogen gas. The SCO concentration was defined as the amount of extracted SCOs per liter working volume $(\mathrm{g} / \mathrm{L})$. The SCO content (lipid content) was represented as a percentage of dry cell weight $(\%, \mathrm{w} / \mathrm{w})$. All experiments were performed in triplicate.

Fatty acid compositions of extracted SCOs produced by each oleaginous yeast were determined using a gas chromatograph 7890A (Agilent, USA) equipped with a flame ionized detector (FID) and a SP-2560 column (Sigma-Aldrich, USA). The SCO samples were converted to fatty acid methyl esters (FAMEs) by transesterification reaction before analysis following the method of Lin and Lin (2017). All gas chromatography analyses were conducted using the services of the Center for Scientific and Technological Equipment (Suranaree University of Technology, Thailand).

\section{Data analysis}

Statistical analyses were performed by one-way analysis of variance (ANOVA) followed by Tukey's test with a $95 \%$ confidence interval using $\mathrm{R}$ software version 3.6.1 (The R Foundation, Austria).

\section{RESULTS AND DISCUSSION}

\section{Sampling of seaweeds}

Stranded seaweeds from the coastlines of Hadd Nam Rin Beach and Haad Son Krasip Beach were primarily categorized and identified based on their morphology and pigmentation. Only two seaweeds were found during the winter study season in February and identified as brown algae belonging to genera Dictyota and Padina in Phylum Ochrophyta. They were named Dictyota sp. strain A (Figure 3A) and Padina sp. strain B (Figure 3B). Some specimens of seaweed blades and stipes were preserved at the Faculty of Science, Energy and Environment, King Mongkut's University of Technology North Bangkok, Thailand. The seaweeds were subsequently dried, weighed, and ground to a fine powder. Results showed that Dictyota sp. strain A was the most abundant seaweed in Hadd Nam Rin Beach and Haad Son Krasip Beach, with dry weight at $91.08 \%$ of the total collected seaweeds. The other seaweed, Padina sp. strain B sparsely appeared on the study shores with dry weight at $8.92 \%$ of the total collected seaweeds.

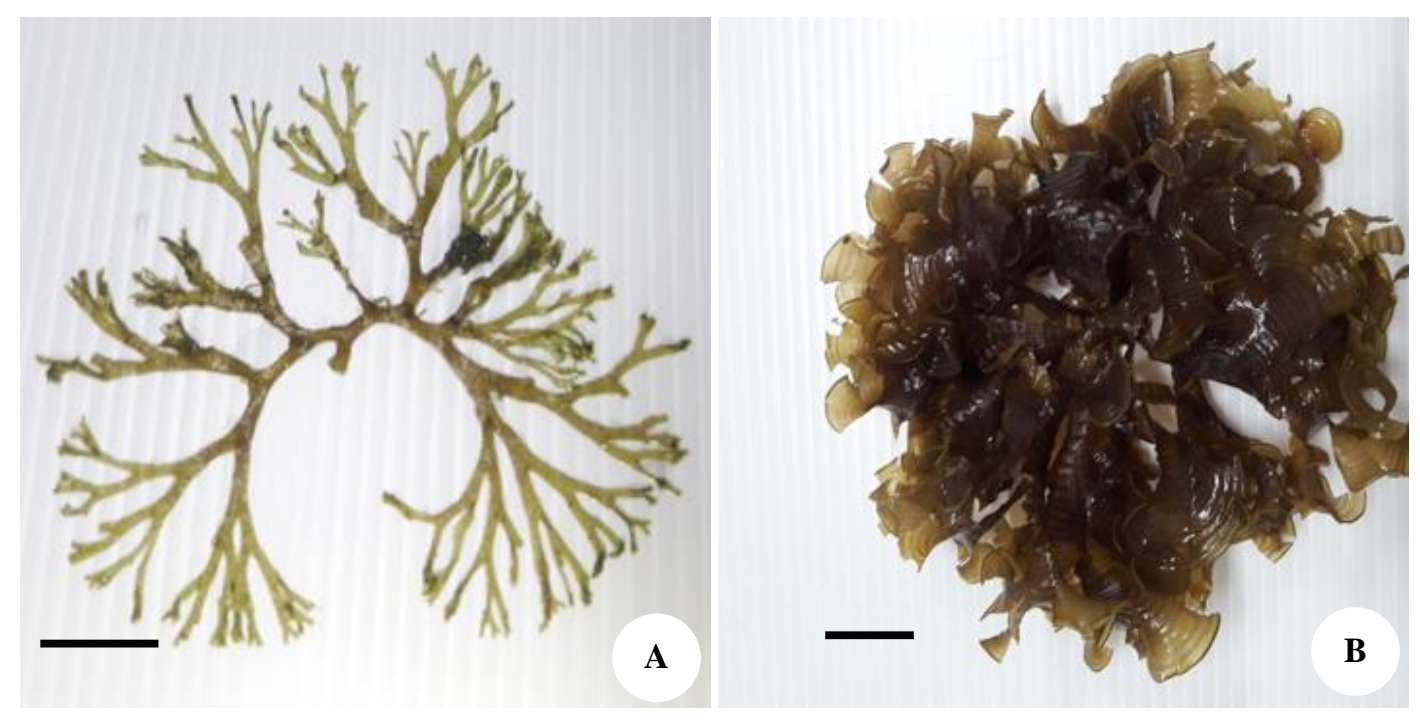

Figure 3. Primary identification of stranded seaweeds based on dominant morphology and pigmentation. A. Dictyota sp. strain A, B.Padina sp. strain B. Bar $=2 \mathrm{~cm}$ 


\section{Species identification of seaweeds by $18 S$ rDNA amplification}

Dictyota sp. strain A and Padina sp. strain B were genetically identified by analysis of $18 \mathrm{~S}$ rDNA. Alignment results using the BLASTn program showed that Dictyota sp. strain A was closely related to $D$. dichotoma strain SZKIZ047 with $99.45 \%$ identity, while Padina sp. strain B was closely related to $P$. australis strain GUMTG035 at $98.20 \%$ identity (Table 1). A phylogenetic tree using the neighbor-joining (NJ) method with 100,000 bootstrap replications is shown in Figure 4. All 18S rDNA sequences from this study were deposited in the GenBank database of NCBI under the accession numbers MT291824 and MT291865, as previously mentioned. Therefore, Dictyota sp. strain A was confidently designated as D. dichotoma strain A, and Padina sp. strain B was assigned to $P$. australis strain B.
Chemical composition analysis of $D$. dichotoma strain A

Dictyota dichotoma strain A was considered as the representative seaweed for the analysis of chemical composition since it was abundant on Hadd Nam Rin Beach and Haad Son Krasip Beach. Moisture content of $D$. dichotoma strain A was $7.57 \pm 0.05 \mathrm{~g}$ per $100 \mathrm{~g}$ of dried seaweed. It was not a good nitrogen source as the protein content by the Kjeldahl method $(\mathrm{N} \times 6.25)$ was found to be $14.66 \pm 0.05 \mathrm{~g}$ per $100 \mathrm{~g}$ of dried seaweed. A small amount of fat was detected in this seaweed at $1.65 \pm 0.01 \mathrm{~g}$ per $100 \mathrm{~g}$ of dried seaweed. Results suggested that D. dichotoma strain A was a satisfying carbon source because total carbohydrate recorded a maximum chemical composition of $52.47 \pm 0.05 \mathrm{~g}$ per $100 \mathrm{~g}$ of dried seaweed. The contents of five sugars comprising glucose, fructose, lactose, maltose, and sucrose were considered as total sugar of $1.21 \pm 0.01 \mathrm{~g}$ per $100 \mathrm{~g}$ of dried seaweed, while the ash content was $23.64 \pm 0.04 \mathrm{~g}$ per $100 \mathrm{~g}$ of dried seaweed.

Table 1. Percentage of $18 \mathrm{~S}$ rDNA sequences for the two stranded seaweeds

\begin{tabular}{ccccc}
\hline \multicolumn{1}{c}{ Seaweed } & Closely related seaweed & $\begin{array}{c}\text { GenBank accession } \\
\text { No. (Database) }\end{array}$ & $\begin{array}{c}\text { Identity } \\
(\%)\end{array}$ & $\begin{array}{c}\text { GenBank accession } \\
\text { No. (Deposited) }\end{array}$ \\
\hline Dictyota sp. strain A & Dictyota dichotoma strain SZKIZ047 & AB087107.1 & 99.45 & \multirow{2}{*}{ MT291824 } \\
Padina sp. strain B & Padina australis strain GUMTG035 & AB087124.1 & 98.20 & MT291865 \\
\hline
\end{tabular}

Note: * Identity results were analyzed on April $6^{\text {th }}, 2020$.

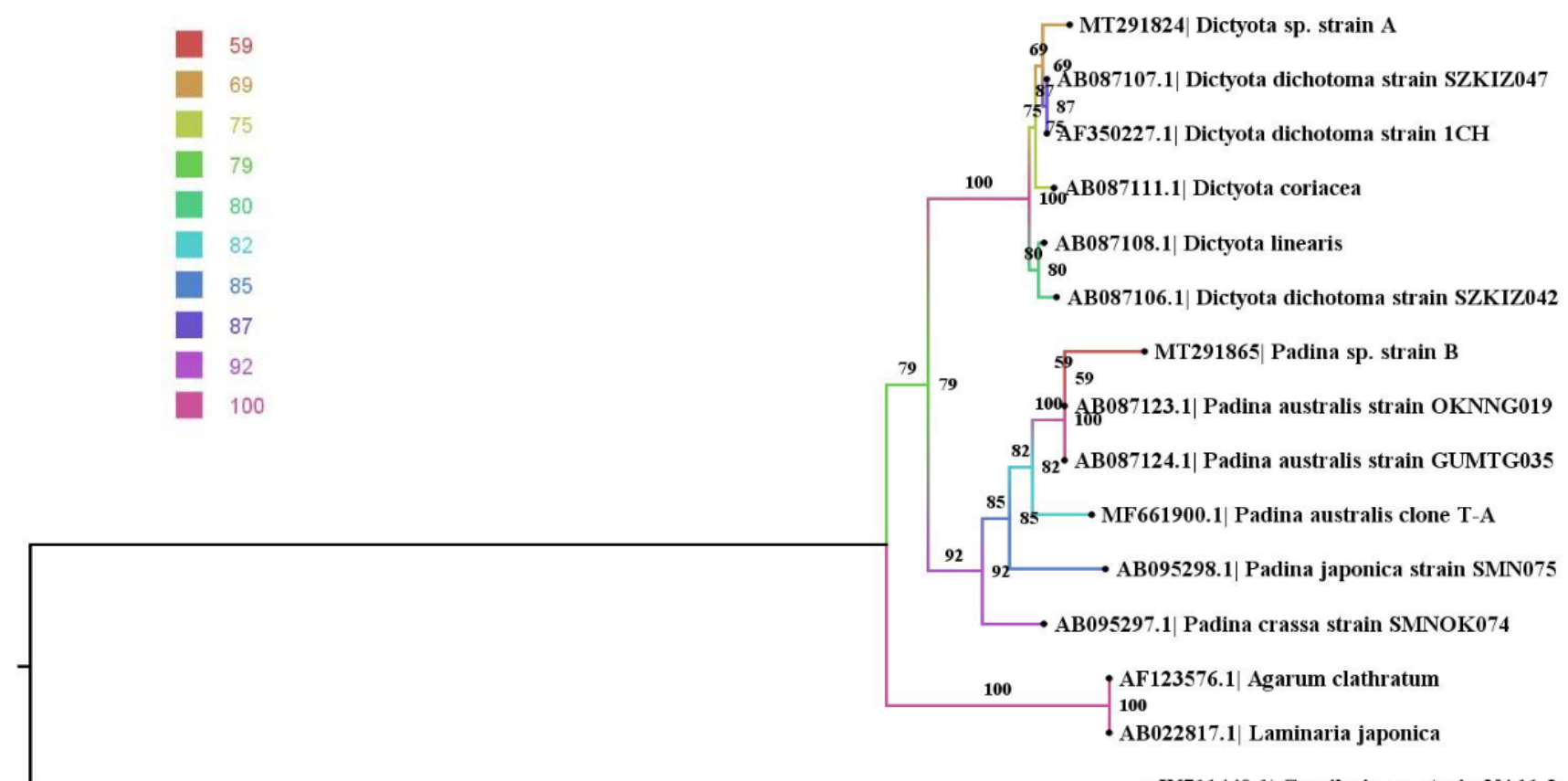

JN711440.1| Gracilaria sp. strain NA11-2

$$
0.02
$$

Figure 4. Phylogenetic tree of $18 \mathrm{~S}$ rDNA for the two stranded seaweeds using the neighbor-joining (NJ) method with 100,000 bootstrap replications. The phylogenetic tree was generated by the SeaView program version 4.6 .4 


\section{Culture and growth of oleaginous yeasts in medium} prepared from $D$. dichotoma strain $A$

Three oleaginous yeasts were cultured in medium prepared from D. dichotoma strain A without supplementing any other nutrients. Their growths were monitored every 24 hours for 120 hours by measurement of $\mathrm{OD}_{600}$. Results showed that all oleaginous yeasts thrived well in this medium, indicating that the carbon source and other nutrients extracted from $D$. dichotoma strain A were sufficient for the growth and survival of oleaginous yeasts. Their growths entered the log phase during 24-72 hours of incubation and the stationary phase after 96 hours of incubation. C. albidus strain TISTR 5103 exhibited significantly better growth than the other yeasts during the $\log$ phase. Growth phases of all oleaginous yeasts are shown in Figure 5.

\section{Determination of dry cell weight and SCO content of oleaginous yeasts}

Cells of the three oleaginous yeasts were measured for dry weight and SCO content after 120 hours of incubation. C. albidus strain TISTR 5103 recorded higher dry weight than the other yeasts that directly correlated to its growth obtained from $\mathrm{OD}_{600}$. Dry weight was achieved at $3.24 \pm$ $0.13 \mathrm{~g} / \mathrm{L}$. $R$. toruloides strain TISTR 5186 and $Y$. lipolytica strain TISTR 5212 showed less dry weight than $C$. albidus strain TISTR 5103 by approximately 50\%. Dry cell weights of the three oleaginous yeasts are reported in Table 2. The SCO concentration and SCO content indicated intracellular lipid accumulation in oleaginous yeasts. The $\mathrm{SCO}$ concentration recorded the weight of SCOs accumulated in the oleaginous yeast per liter of culture volume, whereas SCO content was the percentage of SCOs per dry weight of yeast cells. C. albidus strain TISTR 5103 was the most SCO accumulating yeast with SCO concentration of $1.66 \pm 0.04 \mathrm{~g} / \mathrm{L}$ and significantly higher SCO content of $51.26 \pm 2.99 \%$, while $Y$. lipolytica strain TISTR 5212 showed reduced SCO production. SCO concentration and SCO contents of the three studied oleaginous yeasts are shown in Table 2 .

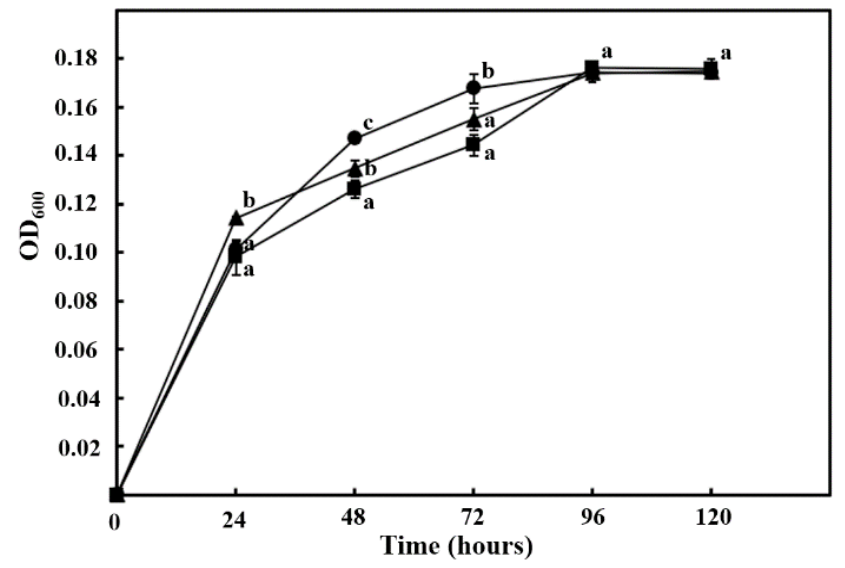

Figure 5. Growth phases for the three oleaginous yeasts cultured in medium prepared from $D$. dichotoma strain A. C. albidus strain TISTR $5103(\mathbf{O}), R$. toruloides strain TISTR $5186(\mathbf{\Delta})$ and $Y$. lipolytica strain TISTR 5212 (ם). Error bars represent the standard deviation of three replicates. Mean values for the same incubation time followed by the same letter were not significantly different according to Tukey's test $(p<0.05)$

Table 2. Dry cell weight and SCO production for the three oleaginous yeasts

\begin{tabular}{lccc}
\hline Oleaginous yeast & $\begin{array}{c}\text { Dry cell weight } \\
(\mathrm{g} / \mathrm{L})\end{array}$ & $\begin{array}{c}\text { SCO concentration } \\
(\mathrm{g} / \mathrm{L})\end{array}$ & $\begin{array}{c}\text { SCO content }(\text { or lipid } \\
\text { content) }(\%, \mathbf{w} / \mathbf{w})\end{array}$ \\
\hline C. albidus strain TISTR 5103 & $3.24 \pm 0.13^{\mathrm{b}}$ & $1.66 \pm 0.04^{\mathrm{c}}$ & $51.26 \pm 2.99^{\mathrm{c}}$ \\
R. toruloides strain TISTR 5186 & $1.63 \pm 0.07^{\mathrm{a}}$ & $0.62 \pm 0.06^{\mathrm{b}}$ & $37.76 \pm 3.50^{\mathrm{b}}$ \\
Y. lipolytica strain TISTR 5212 & $1.58 \pm 0.16^{\mathrm{a}}$ & $0.39 \pm 0.02^{\mathrm{a}}$ & $24.85 \pm 1.91^{\mathrm{a}}$ \\
\hline
\end{tabular}

Note: Mean values in the same column followed by the same letter were not significantly different according to Tukey's test $(p<0.05)$.

Table 3. Fatty acid methyl ester (FAME) profile for the three oleaginous yeasts

\begin{tabular}{lccc}
\hline \multirow{2}{*}{ FAME profile } & \multicolumn{3}{c}{ Percentage of FAME in SCOs (\%) of three oleaginous yeasts } \\
\cline { 2 - 4 } & C. albidus strain TISTR 5103 & R. toruloides strain TISTR 5186 & Y. lipolytica strain TISTR 5212 \\
\hline Capric AME (C10:0) & 0.12 & - & 0.15 \\
Undecanoic AME (C11:0) & - & - & 0.23 \\
Lauric AME (C12:0) & 0.09 & - & 0.38 \\
Myristic AME (C14:0) & 1.12 & 0.68 & 1.27 \\
Pentadecenoic AME (C15:0) & 0.17 & 0.17 & 0.48 \\
Pentadecenoic (cis-10) AME (C15:1) & 0.36 & 0.35 & 0.42 \\
Palmitic AME (C16:0) & 36.46 & 14.96 & 35.12 \\
Palmitoleic AME (C16:1) & 0.56 & 1.54 & 2.08 \\
Heptadecenoic AME (C17:1) & - & 0.34 & 0.69 \\
Stearic AME (C18:0) & 38.66 & 6.43 & 35.02 \\
Oleic AME (C18:1n-9c) & 12.99 & 49.56 & 10.91 \\
Linoleic AME (C18:2n-6t) & 0.75 & - & 10.67 \\
Linoleic AME (C18:2n-6c) & 5.38 & 23.48 & - \\
Linolenic AME (C18:3n-6) & 0.69 & 0.51 & - \\
Eicosenoic AME (C20:1) & - & 1.21 & - \\
Henicosanoic AME (C21:0) & - & 0.47 & - \\
Erucic AME (C22:1n-9) & 2.65 & 0.29 & 2.01
\end{tabular}




\section{Determination of fatty acid composition in SCOs}

Fatty acids in SCOs obtained from the three oleaginous yeasts were converted to fatty acid methyl esters (FAMEs) by transesterification and analyzed for FAME profiles by gas chromatography. Results showed that all oleaginous yeasts yielded different FAME profiles with $\mathrm{C} 10$-fatty acid to C22-fatty acid. They mainly produced long-chain fatty acids with 16 and 18 carbon atoms. C. albidus strain TISTR 5103 and $Y$. lipolytica strain TISTR 5212 produced the most saturated fatty acids comprising palmitic acid (C16:0) and stearic acid (C18:0) ranging 35.0-38.7\%. Interestingly, $R$. toruloides strain TISTR 5186 produced different dominant fatty acids as unsaturated $\mathrm{C} 18$-fatty acids comprising oleic acid (C18:1n-9c) of $49.5 \%$ and linoleic acid (C18:2n-6c) of $23.5 \%$. FAME profiles for the three oleaginous yeasts are shown in Table 3.

\section{Discussion}

Marine benthic algae found in the Gulf of Thailand belong to four Phyla of Chlorophyta, Cyanobacteria, Ochrophyta, and Rhodophyta (Titioatchasai et al. 2019). Here, the brown seaweeds stranded on the coastlines of Hadd Nam Rin Beach and Haad Son Krasip Beach in Eastern Thailand were designated as D. dichotoma strain A and P. australis strain B of Phylum Ochrophyta. Dominant characteristics of Dictyota species are dichotomously branched, flattened, and brown in color (Baweja et al. 2016). D. dichotoma plays a particularly important role in marine productivity (Mantiri et al. 2019). Padina species are calcified brown seaweeds with fan-shaped fronds light brown and whitish in color due to light calcification (Baweja et al. 2016; Mantiri et al. 2019). These two seaweeds are the common seaweeds found in coastal Thailand. D. dichotoma and P. australis were reported as commonly found from January to March in Trat Province on the east coast of Thailand (Petsut et al. 2012). Phang et al. (2016) reported that there were eight species of Dictyota and ten species of Padina in the Gulf of Thailand and the Andaman Sea. P. australis is widely distributed in several Southeast Asian countries including Thailand, The Philippines, Singapore, Vietnam, Indonesia, and Malaysia, while $D$. dichotoma is also found in Southeast Asia except for Indonesia and Malaysia.

Morphological traits and high phenotypic plasticity have become the main bottlenecks in seaweed identification. Moreover, identification based on morphology is almost impossible especially when distinctive characteristics are absent (Herroro et al. 2010). The identification of Dictyota species is challenging due to their phenotypic plasticity and poor species delineation (Lopes-Filho et al. 2017). Likewise, Padina species are also taxonomically challenging due to their phenotypic plasticity coupled with a poor understanding of reliable morphological characters (Win et al. 2018). Therefore, genetic analysis based on rDNA could help to clarify taxonomy and differentiation among the seaweeds (Elsaied et al. 2015). Two stranded seaweeds in this study were genetically identified by sequence analysis of their $18 \mathrm{~S}$ rDNA and taxonomic results were clarified. The $18 \mathrm{~S}$ rDNA obtained were deposited in the GenBank database of NCBI under the approved accession numbers.

The most abundant chemical composition of $D$. dichotoma strain A was carbohydrates, indicating a satisfying carbon source, and comprised several common sugars such as glucose, fructose, lactose, maltose, and sucrose based on total sugar analysis. The main carbohydrate compounds in brown seaweed, except for the common sugars were alginate, fucoidan, laminaran, and mannitol ( $\mathrm{Xu}$ et al. 2014; Malyarenko et al. 2019). Carbohydrates were reported as the most abundant component of macroalgae based on the proximate composition analysis (Omer et al. 2013; Radha 2018). Protein content of seaweeds varied due to many factors such as species, seasons, and geographic area (Radha 2018). The little amount of fat detected in D. dichotoma strain A was supported by Radha (2018) that revealed the crude fat content of most seaweeds was generally less than $3.0 \%$. Composition of fatty acids in $D$. dichotoma extracts showed that palmitic acid (C16:0) was the most abundant (Bakar et al. 2017). Seaweed usually contains high ash contents of approximately 20\% (Radha, 2018).

Recently, several seaweeds have been studied as a feedstock for SCO production. Xu et al. (2015) selected $L$. japonica ( $S$. japonica) as model marine biomass for the cultivation of four different oleaginous yeasts to produce SCOs by the repeated batch system. Results showed that the oleaginous yeast, C. curvatus strain ATCC 20509, yielded the highest SCO content at $61 \%$. Laminaria residue hydrolysates from the kelp industry were used for SCO production by two species of oleaginous yeasts, Rhodosporidium toruloides strain Y4 and Rhodotorula glutinis strain AS 2.107. Results showed that $R$. toruloides strain Y4 yielded $37.6 \%$ and R. glutinis strain AS 2.107 yielded $22.2 \%$ of SCO contents (Zhang et al. 2016). The $S$. latissima seaweed was hydrolyzed and cultured by oleaginous yeast, Metschnikowia pulcherrima in a stirred tank reactor fermentation and $37.2 \%$ SCO was achieved (Abeln et al. 2019).

Utilization of D. dichotoma strain A was prepared as a growth medium without supplementing any other nutrients for the culture of three oleaginous yeasts. Results showed that $\mathrm{OD}_{600}$ increased over time, indicating that oleaginous yeasts utilized the carbon source and other nutrients in the prepared medium for growth. Acetyl-CoA molecules in cytosol of yeast cells serve as fatty acid precursors (Fakas, 2017). Biosynthesis of fatty acids is initiated when growth media are starved of nitrogen (Kumar et al. 2017). Fortunately, D. dichotoma strain A was evaluated as a deficient source of nitrogen. Oleaginous yeasts are capable of biosynthesis and can accumulate more than $20 \%$ of their cell mass as intracellular lipids. In this study, all oleaginous yeasts accumulated SCOs at more than $20 \%$ of their dry weight. C. albidus strain TISTR 5103 was the most effective oleaginous yeast cultured in the seaweed medium yielding $51.2 \%$ of SCO content. Fatty acid compositions of SCOs produced from the three oleaginous yeasts were analyzed. Results showed palmitic acid (C16:0), stearic acid (C18:0), oleic acid (C18:1n-9c), and linoleic acid 
(C18:2n-6c) as the highest fatty acids contents. These fatty acids are commonly found in various vegetable oils. Giakoumis (2018) studied the physicochemical properties and fatty acid composition of 22 vegetable oils. Findings indicated that saturated fatty acids comprising palmitic acid and stearic acid were mostly found from coconut, palm, and mahua oils. Unsaturated fatty acids including oleic acid and linoleic acid are highly presented in olive, rapeseed/canola, sunflower, corn, and soybean oils. Many previous studies reported that SCOs produced by yeasts had similar fatty acid profiles to various vegetable oils (Xu et al. 2014; Gientka et al.2017; Saran et al. 2017; Cho and Park, 2018). This characteristic of SCOs promotes their use as edible oil, and an appropriate alternative for secondgeneration fuel production such as biodiesel.

In conclusion, the stranded seaweeds were identified as $D$. dichotoma strain A and P. australis strain B based on their dominant morphology and 18S rDNA sequence analyses. The most abundant seaweed, $D$. dichotoma strain A, was considered the sole carbon source for the cultivation of three different oleaginous yeasts. The oleaginous yeasts accumulated SCOs in a medium prepared from Dictyota seaweed. D. dichotoma strain A showed potential for yeast cultivation at low-cost with a high-value carbon source. The SCOs produced from the oleaginous yeasts revealed fatty acid profiles similar to vegetable oils, with potential for use in various industrial applications such as biofuels.

\section{ACKNOWLEDGEMENTS}

This research was funded by King Mongkut's University of Technology North Bangkok, Thailand. Contract no. KMUTNB-61-DRIVE-005.

\section{REFERENCES}

AOAC. 2016. Official Methods of Analysis of AOAC International 20th ed. AOAC International, Maryland.

Abeln F, Fan J, Budarin VL, Briers H, Parsons S, Allen MJ, Henk DA, Clark J, Chuck CJ. 2019. Lipid production through the single-step microwave hydrolysis of macroalgae using the oleaginous yeast Metschnikowia pulcherrima. Algal Res 38: 1-9. DOI: 10.1016/j.algal.2019.101411

Bakar K, Mohamad H, Latip J, Tan HS, Herng GM. 2017. Fatty acids compositions of Sargassum granuliferum and Dictyota dichotoma and their anti-fouling activities. J Sustain Sci Manag 12 (2): 8-16.

Baweja P, Kumar S, Sahoo D, Levine I. 2016. Biology of seaweeds. In Fleurence J, Levine I (eds.). Seaweed in Health and Disease Prevention. Elsevier, Amsterdam.

Buschmann AH, Camus C, Infante J, Neori A, Israel Á, HernándezGonzález MC, Pereda SV, Gomez-Pinchetti JL, Golberg A, TadmorShalev N, Critchley AT. 2017. Seaweed production: overview of the global state of exploitation, farming and emerging research activity. Eur J Phycol 52 (4): 391-406.

Byreddy AR, Gupta A, Barrow CJ, Puri M. 2015. Comparison of cell disruption methods for improving lipid extraction from Thraustochytrid strains. Mar Drugs 13 (8): 5111-5127.

Chankaew W, Luaelae W, Phromhom S. 2016. Diversity and screening of biological activity of red macroalgae from Trang watershed area, Thailand. International J Agric Technol 12: 2113-2122.

Cho HU, Park JM. 2018. Biodiesel production by various oleaginous microorganisms from organic wastes. Bioresour Technol 256: $502-$ 508.
Coppejans E, Prathep A, Lewmanomont K, Hayashizaki K, De Clerck O, Leliaert F, Terada R. 2017. Seaweeds and seagrasses of the Southern Andaman Sea coast of Thailand. Kagoshima University Museum, Kagoshima.

Elsaied HE, Hassaan M, Taleb HTA. 2015. Genetic and nutritional characterization of some macrophytes, inhabiting the Bardawil Lagoon, Sinai, Egypt. Egypt J Aquat Res 41: 315-322.

Fakas S. 2017. Lipid biosynthesis in yeasts: a comparison of the lipid biosynthetic pathway between the model nonoleaginous yeast Saccharomyces cerevisiae and the model oleaginous yeast Yarrowia lipolytica. Eng Life Sci 17: 292-302.

Feng J, Guo Y, Zhang X, Wang G, Lv J, Liu Q, Xie S. 2016. Identification and characterization of a symbiotic alga from soil bryophyte for lipid profiles. Biol Open 5: 1317-1323.

Gaillande C, Payri C, Remoissenet G, Zubia M. 2017. Caulerpa consumption, nutritional value and farming in the Indo-Pacific region. J Applied Phycol 29: 2249-2266.

Giakoumis EG. 2018. Analysis of 22 vegetable oils' physicochemical properties and fatty acid composition on a statistical basis, and correlation with the degree of unsaturation. Renew Energ 126: 403 419.

Gientka I, Kieliszek M, Jermacz K, Błażejak S. 2017. Identification and characterization of oleaginous yeast isolated from kefir and its ability to accumulate intracellular fats in deproteinated potato wastewater with different carbon sources. BioMed Res Intl 2017: 1-19. DOI: $10.1155 / 2017 / 6061042$

Herrero B, Madriñán M, Vieites JM, Espiñeira M. 2010. Rapid identification of seaweeds in food products by PCR combined with ALF-RFLP and FINS Methodologies. J Agricultural and Food Chemistry 58: 11586-11592.

Kumar D, Singh B, Korstad J. 2017. Utilization of lignocellulosic biomass by oleaginous yeast and bacteria for production of biodiesel and renewable diesel. Renew Sustain Energ Rev 73: 654-671.

Lin CY, Lin BY. 2017. Comparison of fatty acid compositions and fuel characteristics of biodiesels made from Isochrysis galbana lipids and from used cooking oil. J Mar Sci Technol 25 (4): 399-403.

Lopes-Filho EAP, Salgueiro F, Nascimento SM, Gauna MC, Parodi ER, De Paula JC. 2017. Molecular evidence of the presence of Dictyota dichotoma (Dictyotales: Phaeophyceae) in Argentina based on sequences from mtDNA and cpDNA and a discussion of its possible origin. New Zealand J Botany 55 (3): 293-305.

López BA, Macaya EC, Rivadeneira MM, Tala F, Tellier F, Thiel M. 2018. Epibiont communities on stranded kelp rafts of Durvillaea antarctica (Fucales, Phaeophyceae)-Do positive interactions facilitate range extensions?. J Biogeography 45: 1833-1845.

Kim JK, Yarish C, Hwang EK, Park M, Kim Y. 2017. Seaweed aquaculture: cultivation technologies, challenges and its ecosystem services. Algae 32 (1): 1-13. DOI: 10.4490/algae.2017.32.3.3

Malyarenko OS, Usoltseva RV, Zvyagintseva TN, Ermakova SP. 2019. Laminaran from brown alga Dictyota dichotoma and its sulfated derivative as radioprotectors and radiosensitizers in melanoma therapy. Carbohydrate Polymers 206: 539-547.

Mantiri DMH, Kepel RC, Manoppo H, Paulus JJH, Paransa DS, Nasprianto. 2019. Metals in seawater, sediment and Padina australis (Hauck, 1887) algae in the waters of North Sulawesi. AACL Bioflux 12 (3): 840-850.

Mantri VA, Kavale MG, Kazi MA. 2020. Seaweed biodiversity of India: reviewing current knowledge to identify gaps, challenges, and opportunities. Diversity 12 (1): 1-22. DOI: 10.3390/d12010013

Omer HH, Abdullatif BM, Al-Kazan MM, Adel ME. 2013. Red Sea water and biochemical composition of seaweeds at southern coast of Jeddah, Saudi Arabia. Life Sci J 10 (4): 1073-1080.

Patel A, Arora N, Mehtani J, Pruthi V, Pruthi PA. 2017. Assessment of fuel properties on the basis of fatty acid profiles of oleaginous yeast for potential biodiesel production. Ren Sustain Energ Rev 77: 604 616.

Petsut N, Chirapart A, Keawnern M. 2012. A stability assessment on seasonal variation of seaweed beds in the Trat peninsula of Thailand. Biodiv J 3 (3): 229-236.

Phang SM, Yeong HY, Ganzon-Fortes ET, Lewmanomont K, Prathep A, Hau LN, Gerung GS, Tan KS. 2016. Marine algae of the South China Sea bordered by Indonesia, Malaysia, Philippines, Singapore, Thailand and Vietnam. Raffles Bull Zool 34: 13-59.

Prathep A, Pongparadon S, Darakrai A, Wichachucherd B, Sinutok S. 2011. Diversity and distribution of seaweed at Khanom-Mu Ko Thale 
Tai National Park, Nakhon $\mathrm{Si}$ Thammarat Province, Thailand. Songklanakarin J Sci Technol 33 (6): 633-640.

Qin L, Liu L, Zeng AP, Wei D. 2017. From low-cost substrates to singlecell oils synthesized by oleaginous yeasts. Bioresour Technol 245: 1507-1519.

Radha P. 2018. Proximate analysis and mineral composition of seaweeds of Manamelkudi Coast, Pudukkottai District, India. Intl J Curr Microbiol Appl Sci 7 (8): 3121-3128.

Sadhukhan J, Gadkari S, Martinez-Hernandez E, Ng KS, Shemfe M, Torres-Garcia E, Lynch J. 2019. Novel macroalgae (seaweed) biorefinery systems for integrated chemical, protein, salt, nutrient and mineral extractions and environmental protection by green synthesis and life cycle sustainability assessments. Green Chem 21 (10): 2635 2655.

Saran S, Mathur A, Dalal J, Saxena RK. 2017. Process optimization for cultivation and oil accumulation in an oleaginous yeast Rhodosporidium toruloides A29. Fuel 188: 324-331.

Seangkaew J, Bovonsombut S, Peerapornpisal Y. 2016. Species diversity and distribution of mangrove-associated red alga Bostrychia
(Rhodomelaceae, Rhodophyta) from southern Thailand. International J Appl Environ Sci 11 (1): 55-71.

Titioatchasai J, Prathep A, Mayakun J. 2019. Pattern of algal succession in the tropical subtidal coral reef community at Koh Taen, Mu Ko Thale Tai National Park, the Gulf of Thailand. J Fish Environ 43 (3): 11-18.

Win NN, Hanyuda T, Kato A, Kawai H. 2018. Two new species of Padina (Dictyotales, Phaeophyceae) from southern Japan, $P$. ogasawaraensis sp. nov. and $P$. reniformis sp. nov., based on morphology and molecular markers. Phycologia 57 (1): 20-31.

Xu X, Kim JY, Cho HU, Park HR, Park JM. 2015. Bioconversion of volatile fatty acids from macroalgae fermentation into microbial lipids by oleaginous yeast. Chem Eng J 264: 735-743.

Xu X, Kim JY, Oh YR, Park JM. 2014. Production of biodiesel from carbon sources of macroalgae, Laminaria japonica. Bioresour Technol 169: 455-461.

Zhang X, Shen H, Yang X, Wang Q, Yu X, Zhao ZK. 2016. Microbial lipid production by oleaginous yeasts on Laminaria residue hydrolysates. RSC Adv 32: 26490-27259. 